\title{
A study comparing non-gestational diabetes mellitus and gestational diabetes mellitus in antenatal patients in a tertiary care center
}

\author{
Preeti Sharma, Neeta Chaudhary*, Suchitra Singh
}

Department of Obstetrics and Gynecology, Muzaffarnagar Medical College, Muzaffarnagar, Uttar Pradesh, India

Received: 08 January 2020

Accepted: 05 February 2020

\section{* Correspondence:}

Dr. Neeta Chaudhary,

E-mail: drneetachaudhary1261@gmail.com

Copyright: (c) the author(s), publisher and licensee Medip Academy. This is an open-access article distributed under the terms of the Creative Commons Attribution Non-Commercial License, which permits unrestricted non-commercial use, distribution, and reproduction in any medium, provided the original work is properly cited.

\section{ABSTRACT}

Background: Gestational diabetes mellitus is defined as any glucose intolerance with the onset or first recognition during pregnancy. Objectives of this study were to diagnose cases of GDM by screening with DIPSI criteria at less than 28 weeks. And observation and comparison of maternal and perinatal outcome in women diagnosed of GDM in less than 20 weeks and at 24-28 weeks.

Methods: This was the prospective analytical study conducted in the department of obstetrics and gynecology for one year in Muzaffarnagar medical college and Hospital. After history taking, clinical and obstetrics examination 1503 antenatal patients of less than 28 weeks were enrolled underwent screening with DIPSI criteria. Out of which 80 patients with abnormal OGTT of gestational age less than 20 weeks and 69 patients with abnormal OGTT of gestational age $24-28$ weeks.

Results: In early diagnosed GDM group alive and healthy babies were slightly lower as compared with late diagnosed GDM group.

Conclusions: The diagnosis of GDM gives us an opportunity in identifying individuals who will be benefitted by early therapeutic intervention with diet, exercise, and normalizing the weight to delay or prevent the onset of the disease.

Keywords: Diabetes in pregnancy study group of India, Gestational diabetes mellitus, Lower segment caesarean section, Oral glucose tolerance test

\section{INTRODUCTION}

In the Indian context, the prevalence of GDM is steadily increasing from $2 \%$ in 1982 to $16.55 \%$ in $2002 .{ }^{1}$ GDM is $2 \%$ to $14 \%$ prevalent in all pregnant women. ${ }^{2}$ The glucose intolerance seen during pregnancy can be labelled as. ${ }^{3}$

- Diabetes mellitus

- Gestational diabetes mellitus

- Decreased gestational glucose tolerance.

Nearly $50 \%$ of women with GDM will become overt diabetes (type 2) over a period of 5-20 years. ${ }^{4}$ Depending on geographical location and diagnostic methods used, the prevalence of GDM varied from 3.8\%-21\% in different parts of India. ${ }^{5}$ Many studies have been done in the western countries which have reported the prevalence of GDM as high as $9.2 \%$ according to a new report from, centers for disease control and prevention (CDC). Only few studies have been done on Indian population regarding the prevalence and association of GDM with maternal and fetal outcome. The prevalence reported in these studies ranges from $2 \%$ to $14 \% .^{6}$ All these studies have shown that GDM is associated with some adverse maternal and perinatal outcome like pre-eclampsia, placenta previa, oligohydramnios, polyhydraminos, anemia, increased rates of instrumental deliveries and caesarean section, preterm birth, fetal distress maternal 
outcome and macrosomia, low birth weight, hypoglycaemia, hyperbilirubinemia, pre-term birth, shoulder dystocia, meconium aspiration, NICU admission $>24$ hours, IUD/still birth, neonatal sepsis, metabolic complications as neonatal outcome respectively.

\section{Objectives of this study were}

- To diagnose the cases of gestational diabetes mellitus by screening with DIPSI criteria at less than 28 weeks.

- Observation and comparison of maternal and perinatal outcome in women diagnosed of GDM in less than 20 weeks and at 24-28 weeks.

\section{METHODS}

This was the prospective analytical study conducted in the department of obstetrics and gynecology for one year in Muzaffarnagar Medical College and Hospital. The study approved by Institutional Ethical Committee. After history taking, clinical and obstetrics examination 1503 antenatal patients of less than 28 weeks were enrolled underwent screening with DIPSI criteria and were followed up till delivery. The enrolled patients were divided into groups as follows.

\section{Inclusion criteria}

- Singleton pregnancy

- Age 18-35 years

- Gestational age 28 weeks or less at the time of presentation.

\section{Exclusion criteria}

- Multiple pregnancies

- Gestational age of more than 28 weeks

- Already diagnosed case of diabetes mellitus

- Pregnancy with previous caesarean

- Known case of hypertension, renal disease, heart disease, thyroid dysfunction, surgical disorders or any other medical disorder.

Table 1: Gestational diabetes criteria recommended by DIPSI. ${ }^{3}$

\begin{tabular}{|ll|}
\hline Criteria & In pregnancy \\
\hline 2 hours $\geq 200 \mathrm{mg} / \mathrm{dl}$ & Diabetes mellitus \\
\hline 2 hours $\geq 140 \mathrm{mg} / \mathrm{dl}$ & $\begin{array}{l}\text { Gestational diabetes mellitus } \\
(\text { GDM })\end{array}$ \\
\hline 2 hours $\geq 120 \mathrm{mg} / \mathrm{dl}$ & $\begin{array}{l}\text { Decreased gestational glucose } \\
\text { tolerance (DGGT) }\end{array}$ \\
\hline
\end{tabular}

At the first antenatal visit all antenatal women were asked to take 75 gram of anhydrous glucose in 250-300 $\mathrm{ml}$ of water in 5 minutes irrespective of the fasting status and venous plasma glucose was estimated after 2 hours by the GOD-POD (glucose oxidase peroxidase) method. Those patients who had a normal screening test at first visit were subjected to the test again at 24-28 weeks of gestation. The patients were diagnosed by DIPSI as follows (Table 1). ${ }^{3}$

\section{We have divided the patients in two groups}

- Group 1: Include 80 antenatal patients with pog of less than 20 weeks.

- Group 2: Include 69 antenatal patients with pog between 24-28 weeks.

\section{Statistical analysis}

Statistical analysis was done by using Chi square/Fisher's exact test.

\section{RESULTS}

Maximum number of pregnant women in both Groups 1a and $2 \mathrm{a}$ were land into spontaneous labor but rate of induction and augmentation was maximum in Group 2a. Among study Group 2a, more patients were diagnosed as polyhydramnios, preterm labour and with preeclampsia. In Group 1a more antenatal patients were delivered between 38-40 weeks as compared to Group 2a. Vaginal delivery was more common in Group 1a, and LSCS was more common in Group 2a (Table 2).

Mean birth weight was higher in early diagnosed GDM group i.e., 2778.72 grams as compared with late diagnosed GDM group. In early diagnosed GDM group alive and healthy babies were slightly lower as compared with late diagnosed GDM group. In early diagnosed GDM group, $96.25 \%$ babies were alive and healthy, 3 babies were having gross congenital anomalies 1 with congenital diaphragmatic hernia and 2 having neural tube defects. In late diagnosed GDM group, $97.10 \%$ babies were alive and healthy, 2 babies presented with gross congenital anomaly, 1 with anencephaly and other with congenital heart disease,1baby was macrosomic born with birth weight of 4030 grams and 1baby had suffered from erb's paralysis during difficult breech extraction. (Table 3).

\section{DISCUSSION}

GDM is a serious medical complication of pregnancy, which affects $1.1-14.3 \%$ of pregnant women depending on the ethnic and clinical characteristics of the population and the diagnostic test employed. ${ }^{7}$ The prevalence of GDM in India varies from $9.9 \%$ in rural population to $17.8 \%$ in urban areas. ${ }^{8}$

In a survey done by Jiwani A et al including 173 countries, the prevalence of GDM range from $<1 \%$ to $28 \%$ with data derived from expert estimates and single site, multisite and national prevalence assessments and large variations were observed in estimated GDM prevalence ,but direct comparison between countries was difficult due to different diagnostic strategies and subpopulations. ${ }^{9}$ 
Table 2: Maternal outcomes in study Group 1 study Group 2.

\begin{tabular}{|llll|}
\hline $\begin{array}{l}\text { Maternal outcomes } \\
\text { Labour }\end{array}$ & $\begin{array}{l}\text { Study Group 1 } \\
\text { Early diagnosed GDM (N = 80) }\end{array}$ & $\begin{array}{l}\text { Study Group 2 } \\
\text { Late diagnosed GDM (N = 69) }\end{array}$ & p value \\
\hline Spontaneous & $42(52.5 \%)$ & $30(43.47 \%)$ & 0.112 \\
\hline Induced & $31(38.75 \%)$ & $27(39.13 \%)$ & 0.221 \\
\hline Augmented & $7(8.75 \%)$ & $12(17.39 \%)$ & 0.134 \\
\hline Antenatal complications & & $6(8.69 \%)$ & 0.320 \\
\hline Polyhydraminos & $4(5.0 \%)$ & $2(2.89 \%)$ & 0.274 \\
\hline Preterm labour $(<37$ weeks) & $2(2.5 \%)$ & $7(10.14 \%)$ & 0.036 \\
\hline Pre-eclampsia & $2(2.5 \%)$ & $0(0.00 \%)$ & - \\
\hline Placental abruption & $0(0.00 \%)$ & $54(78.26 \%)$ & 0.022 \\
\hline Uneventful & $72(90.0 \%)$ & & 0.030 \\
\hline Period of gestation at delivery & & $2(2.89 \%)$ & 0.024 \\
\hline$>40$ weeks & $10(12.5 \%)$ & $40(57.97 \%)$ & $<0.001$ \\
\hline $38-40$ weeks & $56(70.0 \%)$ & $26(37.68 \%)$ & 0.138 \\
\hline $36-38$ weeks & $10(12.5 \%)$ & $1(1.44 \%)$ & 0.118 \\
\hline $34-36$ weeks & $2(2.5 \%)$ & $0(0.00 \%)$ & 0.014 \\
\hline$<34$ weeks & $2(2.5 \%)$ & $41(59.42 \%)$ & 0.006 \\
\hline Mode of delivery & $58(72.5 \%)$ & $27(39.13 \%)$ & 0.044 \\
\hline Vaginal & $17(21.25 \%)$ & $1(1.44 \%)$ & \\
\hline LSCS & $5(6.25 \%)$ & & \\
\hline Instrumental & & & \\
\hline
\end{tabular}

Table 3: Maternal outcomes in study Group 1 study Group 2.

\begin{tabular}{|c|c|c|c|}
\hline Fetal outcomes & $\begin{array}{l}\text { Study Group } 1 \\
\text { Early diagnosed GDM }(\mathbf{N}=\mathbf{8 0})\end{array}$ & $\begin{array}{l}\text { Study Group } 2 \\
\text { Late diagnosed GDM }(\mathrm{N}=69)\end{array}$ & p value \\
\hline \multicolumn{4}{|l|}{ Birth weight (grams) } \\
\hline Mean \pm SD & $2778.72 \pm 374.18$ & $2655.56 \pm 508.34$ & 0.268 \\
\hline \multicolumn{4}{|l|}{ (statistical test used: Mann Whitney test). } \\
\hline \multicolumn{4}{|l|}{ Baby status } \\
\hline Alive & $77(96.25 \%)$ & $67(97.10 \%)$ & 0.182 \\
\hline Fresh stillbirth & $2(2.5 \%)$ & $1(1.44 \%)$ & 0.143 \\
\hline Macerated stillbirth & $1(1.25 \%)$ & $1(1.44 \%)$ & 0.432 \\
\hline \multicolumn{4}{|c|}{ (statistical test used: Chi square/Fischer's exact test). } \\
\hline \multicolumn{4}{|l|}{ Neonatal complications } \\
\hline Absent & $75(93.75 \%)$ & $64(92.75 \%)$ & 0.290 \\
\hline Gross congenital anomaly & $3(3.75 \%)$ & $2(2.89 \%)$ & 0.248 \\
\hline Macrosomia (birth weight $>4 \mathrm{~kg}$ ) & $0(0.00 \%)$ & $1(1.44 \%)$ & 0.128 \\
\hline Trauma & $0(0.00 \%)$ & $1(1.44 \%)$ & 0.148 \\
\hline Hypoglycemia & $0(0.00 \%)$ & $0(0.00 \%)$ & - \\
\hline Others & $2(2.5 \%)$ & $0(0.00 \%)$ & 0.172 \\
\hline
\end{tabular}

In a random survey performed in various cities in India in 2002-2003, an overall GDM prevalence of $16.55 \%$ was observed (16.2\% in Chennai, $15 \%$ in Thiruvanthapuram, $12 \%$ in Bangalore, $18.8 \%$ in Erode and $17.5 \%$ in Ludhiana). ${ }^{10}$

Another study from south India conducted a prospective screening for GDM in the urban, semi urban and rural areas. A total of 4151, 3960 and 3945 pregnant women were screened in urban, semi urban and rural areas, respectively. GDM was detected in 739 (17.8\%) women in urban, 548 (13.8\%) in semi urban and 392 (9.9\%) in rural areas. Ramachandran et al, have documented prevalence of GDM as low as $0.56 \%$ by using O'Sullivan and Mahan criteria. ${ }^{11}$ Zargar et al reported $3.8 \%$ prevalence of GDM in Kashmiri women. ${ }^{12}$

Seshiah et al reported prevalence of $16.5 \%$ by using WHO criteria. Gajjar et al from Baroda gave prevalence of GDM as $3 \% .^{13}$ 
In a study done at tertiary care hospital in Maharashtra the prevalence of GDM was found to be $7.7 \%$ and women with a single abnormal value on 3-hour OGTT were $13.9 \% .^{14}$

In a recent study by Neelkandan $\mathrm{R}$ et al, the overall prevalence of GDM was $23.3 \%$; out of which $13.9 \%$ women were found to have GDM in the first trimester (12 weeks). $16.7 \%$ in the $13-18$ weeks, 44.1 in the $19-28$ weeks and $25.2 \%$ in the third trimester (28 weeks). ${ }^{15}$

\section{CONCLUSION}

It suggests that if antenatal registration is early, better antenatal care and good surveillance can prevent some of the avoidable antenatal complications thus improving maternal and fetal outcomes. A good fetal outcome can be achieved similar to normal glucose tolerant pregnant women by early registration.

This trend reflects better antenatal care received in pregnant women with antenatal registration in early pregnancy ( $<20$ weeks).

In this study, better maternal outcomes were observed in study Group 1a as compared to study Group 2a which favours early antenatal check-up and registration followed with regular antenatal check-up.

Funding: No funding sources

Conflict of interest: None declared

Ethical approval: The study was approved by the Institutional Ethics Committee

\section{REFERENCES}

1. American diabetes association position statement gestational diabetes care. 1986;9:430-1.

2. American diabetes association position statement in diagnosis and classification of diabetes mellitus. diabetes care. 2011;34(1):S62-9.

3. Seshiah V, Balaji V, Shah SN, Joshi S, Das AK, Sahay BK, et al. Diagnosis of gestational diabetes mellitus in the community. J Assoc Physicians India. 2012;60:15-7.

4. Ferrara A. Increasing prevalence of gestational diabetes mellitus - a public health perspective. Diabetes Care. 2007;30:141-6.

5. Meltzer SJ, Snyder J, Penrod JR, Nudi M, Morin L. Gestational diabetes mellitus screening and diagnosis: a prospective randomized controlled trial comparing costs of one step and two step methods. Br J Obstet Gynecol. 2010;117:407-15.

6. Brody SC, Harris R, Lohr K. Screening for gestational diabetes: a summary of the evidence for the U.S. Preventive Services Task Force. Obstet Gynecol. 2003;101:380-92.

7. National Diabetes Data Group. Diabetes in America $2^{\text {nd }}$ edition Harris M, editor. Betheseda, MD National Institutes of Health; 1995.

8. Subburaj VK. Secretary to Government of India with reference to health and family welfare (P) Department letter (D) No. 356; 2007.

9. Jiwani A, Marseille E, Lohse N, Damm P, Hod M, Kahn JG. Gestational diabetes mellitus: results from a survey of country prevalence and practices. The Journal of Maternal-Fetal Neonat Med. 2012;25(6):600-10.

10. Seshiah V, Balaji V, Balaji MS, Sanjeev CB, Green A. Gestational diabetes mellitus in India. J Assoc Physicians India. 2004;52:707-11.

11. Ramachandran A, Snehalatha C, Shyamala P, Vijay V, Viswanathan M. Prevalence of diabetes in pregnant women - a study from southern India. Diabetes Res Clin Pract. 1994; 25(1):71-4.

12. Zargar AH, Sheikh MI, Bashir MI, Masoodi SR, Laway BA, Wani AI, et al. Prevalence of gestational diabetes mellitus in Kashmiri women from the Indian Subcontinent. Diabetes Res Clin Pract. 2004;66:139-45.

13. Vinita D, Vaishali J, Anjoo A, Amita P, Sushma P, Agarwal CG. Glucometer screening of gestational diabetes. The J Obstet Gynecol India. 2006;56(6):499-501.

14. Swami SR, Mehetre R, Shivane V, Bandgar TR, Menon PS, Shah NS. Prevalence of carbohydrate intolerance of varying degrees in pregnant females in western India (Maharashtra): A hospital-based study. J Indian Med Assoc. 2008;106:712-4.

15. Neelakandan R, Sethu PS. Early universal screening for gestational diabetes mellitus. J Clin Diagn Res. 2014;8(4):12-4.

Cite this article as: Sharma $P$, Chaudhary N, Singh S. A study comparing non-gestational diabetes mellitus and gestational diabetes mellitus in antenatal patients in a tertiary care centre. Int J Reprod Contracept Obstet Gynecol 2020;9:1201-4. 